Article

\title{
Evaluation of Rhamnetin as an Inhibitor of the Pharmacological Effect of Secretory Phospholipase A2
}

\author{
Mariana Novo Belchor 1,2, Henrique Hessel Gaeta ${ }^{2}$, Caroline Fabri Bittencourt Rodrigues ${ }^{2}$, \\ Caroline Ramos da Cruz Costa ${ }^{2}$, Daniela de Oliveira Toyama ${ }^{3}$, Luiz Felipe Domingues Passero ${ }^{2}$, \\ Marcia Dalastra Laurenti ${ }^{4}$ and Marcos Hikari Toyama ${ }^{2, *}$ \\ 1 Postgraduate Program in Food, Nutrition and Health, Federal University of São Paulo, \\ Santos 11015-020, São Paulo, Brazil; belchor.mariana@gmail.com \\ 2 Bioscience Institute, Paulista State University, São Vicente 11330-900, São Paulo, Brazil; \\ henriquehg@gmail.com (H.H.G.); cfabri3@gmail.com (C.F.B.R.); carolsbert@gmail.com (C.R.d.C.C.); \\ felipepassero@yahoo.com.br (L.F.D.P.) \\ 3 Pro-rector of Research, Brazil University, Itaquera 08230-030, São Paulo, Brazil; gaveira@yahoo.com.br \\ 4 Pathology Laboratory of Infectious Diseases (LIM50), Department of Pathology, Medical School of the \\ University of São Paulo, São Paulo 01246-903, Brazil; mdlauren@usp.br (M.D.L.) \\ * Correspondence: marcoshikaritoyama@gmail.com; Tel.: +55-13-35697136
}

Received: 25 July 2017; Accepted: 29 August 2017; Published: 31 August 2017

\begin{abstract}
Rhamnetin (Rhm), 3-O-methylquercetin (3MQ), and Rhamnazin (Rhz) are methylated derivatives of quercetin commonly found in fruits and vegetables that possess antioxidant and anti-inflammatory properties. Phospholipase A2 (PLA2) displays several important roles during acute inflammation; therefore, this study aimed at investigating new compounds able to inhibit this enzyme, besides evaluating creatine kinase (CK) levels and citotoxicity. Methylated quercetins were compared with quercetin $(\mathrm{Q})$ and were incubated with secretory PLA2 (sPLA2) from Bothrops jararacussu to determine their inhibitory activity. Cytotoxic studies were performed by using the J774 cell lineage incubated with quercertins. In vivo tests were performed with Swiss female mice to evaluate decreasing paw edema potential and compounds' CK levels. Structural modifications on sPLA2 were made with circular dichroism (CD). Despite $Q$ and Rhz showing greater enzymatic inhibitory potential, high CK was observed. Rhm exhibited sPLA2 inhibitory potential, no toxicity and, remarkably, it decreased CK levels. The presence of $3 \mathrm{OH}$ on the C-ring of $\mathrm{Rhm}$ may contribute to both its anti-inflammatory and enzymatic inhibition of sPLA2, and the methylation of ring A may provide the increase in cell viability and low CK level induced by sPLA2. These results showed that $\mathrm{Rhm}$ can be a candidate as a natural compound for the development of new anti-inflammatory drugs.
\end{abstract}

Keywords: rhamnetin; methylated quercetins; phospholipase A2; anti-inflammatory; Bothrops jararacussu

\section{Introduction}

Secretory phospholipases A2 (sPLA2) are proteins with a molecular mass of approximately 13 to $20 \mathrm{kDa}$. They are widely found in various animals, such as mammals, and in the venom of snakes, and they are almost exclusively calcium dependent. These enzymes have the same structural elements for enzymatic catalysis and have significant structural similarities among themselves [1-4]. sPLA2 and the calcium-dependent cytosolic PLA2 have the same enzyme triad, which allows these enzymes to hydrolyze membrane glycerophospholipids to produce arachidonic acid and lysophospholipids. Excessive hydrolysis of membrane phospholipids by activated sPLA2 may lead to altered membrane function, leading to functional membrane failure and cell death. In addition, free fatty acids and lysophospholipid hydrolysis products are precursors of bioactive pro-inflammatory mediators, such as eicosanoids and the platelet-activating factor (PAF) [4]. In particular, sPLA2 in snake venom is an 
attractive therapeutic target due to its accessibility, ease of purification and, in the case of sPLA2 in humans, high levels of systemic enzymatic activity, which characterize and contribute to most of the inflammatory disorders, including neurodegenerative diseases. Therefore, the discovery of new inhibitors of sPLA2 is essential to produce new safe and effective drugs with fewer side effects compared to the current therapy $[5,6]$.

Flavonoids are a class of special metabolites from plants, characterized by the flavan nucleus. These compounds are widely distributed in the leaves, seeds, bark, and flowers of plants; in addition, a recent estimate showed that human's intake ranges from $26 \mathrm{mg}$ to $1 \mathrm{~g}$ per day [7]. Quercetin (Q) is a flavonol widely found in tea (Camellia sinemensis), wine, beer, fruits, and vegetables [8]. Additionally, this compound exhibits antioxidant and anti-inflammatory activities [9]. A methylated derivative of Q shows lipophilicity, which promotes the compound's access to the cell. Achyrocline satureioides, Coriandrum sativum, and Rhamnus petiolaris are species that show the presence of 3-O-methylquercetin (3MQ), rhamnetin (Rhm), and rhamnazin (Rhz), respectively, and have anti-inflammatory activities. In all of these cases, there is no evidence of the effect of methylated quercetins, such as Rhm, against inflammation mediated by SPLA2 and the consequent mobilization of arachidonic acid metabolism or the possible side effects, including cytotoxic activities [10-12]. Considering the $Q$ activities, this work aimed at evaluating 3MQ, Rhm, Rhz, and Q regarding this anti-inflammatory function, besides analyzing their cytotoxic activities toward the J774 cell lineage and evaluating the creatine kinase (CK) levels. In addition, the methylation of free hydroxyl groups in flavones results in more metabolically-stable derivatives with superior membrane-penetrating properties and, thus, vastly improves bioavailability, which should improve their ability to act inside cells [13]. The anti-inflammatory effects of Rhm by modulation of kinases, oxidative stress, and suppression of pro-inflammatory mediators have already been observed [11], however, there are no studies that reveal sPLA2's inhibitory action of this compound and the relation of the structure and function with other quercetin derivatives. Thus, in this study, the inhibitory potential of $\mathrm{Q}$ and their methylated derivatives in vitro and in vivo were evaluated against sPLA2 from Bothrops jararacussu. To find safe and effective compounds, cytotoxic effects were evaluated using the cell lineage J774 as a model for cytotoxicity and CK levels were assayed as a model of acute toxicity in vivo.

\section{Results}

\subsection{Purity of sPLA2}

sPLA2 purity was evaluated by high-performance liquid chromatography (HPLC). Figure 1 shows the chromatographic profile of the eluted native sPLA2 from Bothrops jararacussu with a retention time of $22.71 \mathrm{~min}$.

\subsection{Enzymatic, Circular Dichroism, Edema, and Myotoxic and Cytotoxic Effects}

\subsubsection{Enzymatic Assay}

All assays were conducted using sPLA2 from Bothrops jararacussu that was previously incubated with each compound (Figure 2A); under these conditions, 3MQ, Rhm, Rhz, and Q in the enzymatic assay revealed that, among the methylated quercetins, Rhz showed higher inhibition than $3 \mathrm{MQ}$ and Rhm. The inhibitory activity of Rhz was similar to $Q$. Despite the fact that Rhz showed methylation in the $\mathrm{A}$ ring and $\mathrm{B}$ ring, the presence of $3-\mathrm{OH}$ in the $\mathrm{C}$ ring was likely a common group in Rhm, Rhz, and Q flavonols, leading to sPLA2 inhibition (Figure 1B). However, Rhz exhibits a higher inhibition than Rhm due the presence of the methylated group on the B ring. A greater interaction with sPLA2 was observed in Q, showing more inhibition among the quercetins studied. In addition, analysis of the results presented in Figure 2B,A showed that replacement of the $\mathrm{OH}$ group in the $\mathrm{C}$ ring by a methyl group almost completely abolished the inhibitory capacity of 3MQ. 


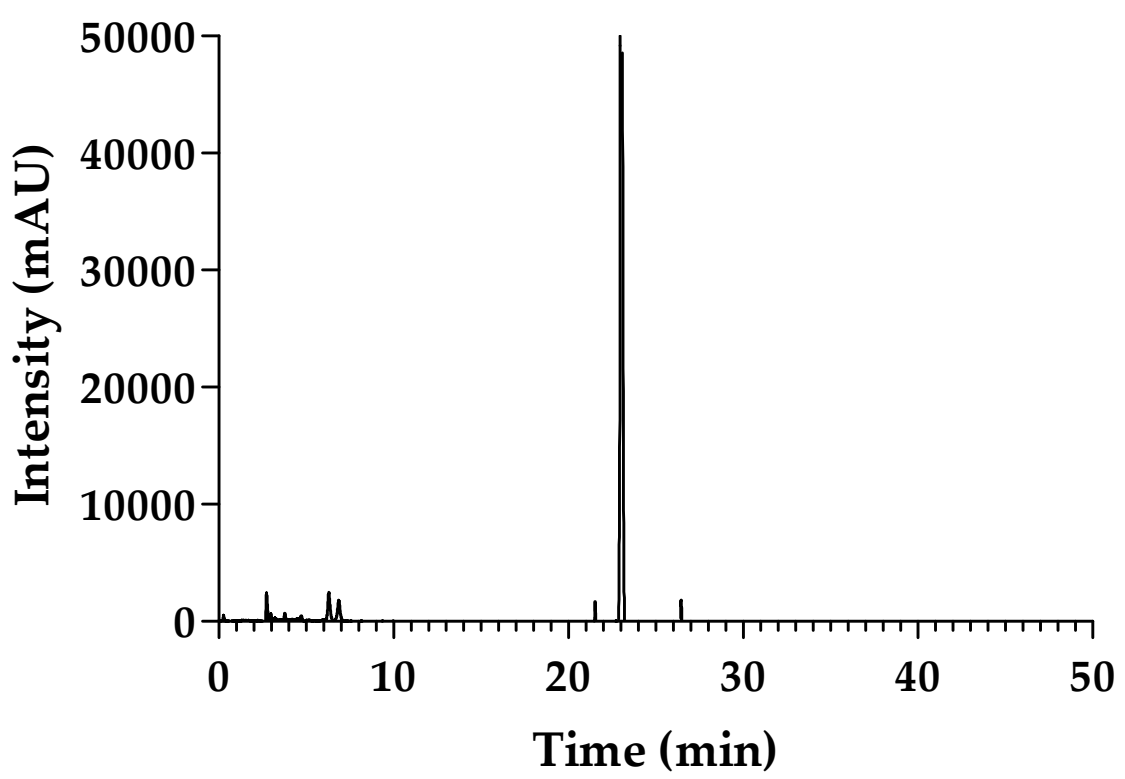

Figure 1. sPLA2 purity profile by high-performance liquid chromatography (HPLC). The enzyme purification was performed with a TSKgel SP-5PW $(7.5 \mathrm{~cm} \mathrm{ID} \times 7.5 \mathrm{~cm} \cdot \mathrm{L})$ using a non-linear gradient with buffer B (ammonium bicarbonate $1.0 \mathrm{M}$ ) at a constant flow rate of $1.0 \mathrm{~mL} / \mathrm{min}$. The active sPLA2 underwent a new chromatographic step on a reverse phase HPLC using a C5 semi-analytical column. In this step, the chromatographic column was pre-equilibrated with buffer A $(0.1 \%$ TFA) for $30 \mathrm{~min}$ at a flow rate of $1 \mathrm{~mL} / \mathrm{min}$. Samples of sPLA2 $(1 \mathrm{mg})$ were dissolved in $250 \mu \mathrm{L}$ of buffer A and separated using the chromatographic column. Elution of the sPLA2 was performed with a continuous linear gradient of buffer B ( $66 \%$ acetonitrile in $0.1 \%$ TFA), and the monitoring of the chromatographic profile was at $280 \mathrm{~nm}$.

\subsubsection{Circular Dichroism}

Modifications in SPLA2 were evaluated via circular dichroism, and the effects in the $\alpha$-helix and $\beta$-sheet are observable in Table 1. Figure $2 \mathrm{C}$ shows the changes as a result of the interactions of quercetins with sPLA2, which occurred mainly in the region corresponding to the $\alpha$-helices. These results reveal the changes in the secondary structure of this protein due to the interaction with 3MQ, Rhm, Rhz, and Q (Figure 2C).

Table 1. Variation of the $\alpha$-helix and $\beta$-sheet percentages in SPLA2 and in the quercetins incubated with the protein.

\begin{tabular}{cccccc}
\hline & sPLA2 & 3MQ & Rhm & Rhz & Q \\
\hline$\alpha$-helix & $45.30 \%$ & $26.80 \%$ & $27.00 \%$ & $54.70 \%$ & $23.40 \%$ \\
$\beta$-sheet & $14.80 \%$ & $18.30 \%$ & $18.00 \%$ & $13.40 \%$ & $18.80 \%$ \\
\hline
\end{tabular}

\subsubsection{Paw Edema Assay of Chemically-Treated sPLA2}

All quercetins showed a significant inhibitor potential against sPLA2; thus, to evaluate the co-protection effect, the edema inhibition potential of the quercetins was evaluated. The compounds were administered $30 \mathrm{~min}$ before sPLA2 application. All flavonols studied for treatment of sPLA2 strongly decreased the maximum edema peak induced by native sPLA2 from Bothrops jararacussu. Moreover, Rhz and Q significantly diminished the edema induced by sPLA2 after 120 min. These results suggest that methylation substituents in the $\mathrm{A}$ and $\mathrm{B}$ ring and the presence of the 3-OH group in the $\mathrm{C}$ ring should play an effective role for the anti-inflammatory effect against edema induced by this native sPLA2 (Figure 2D). 


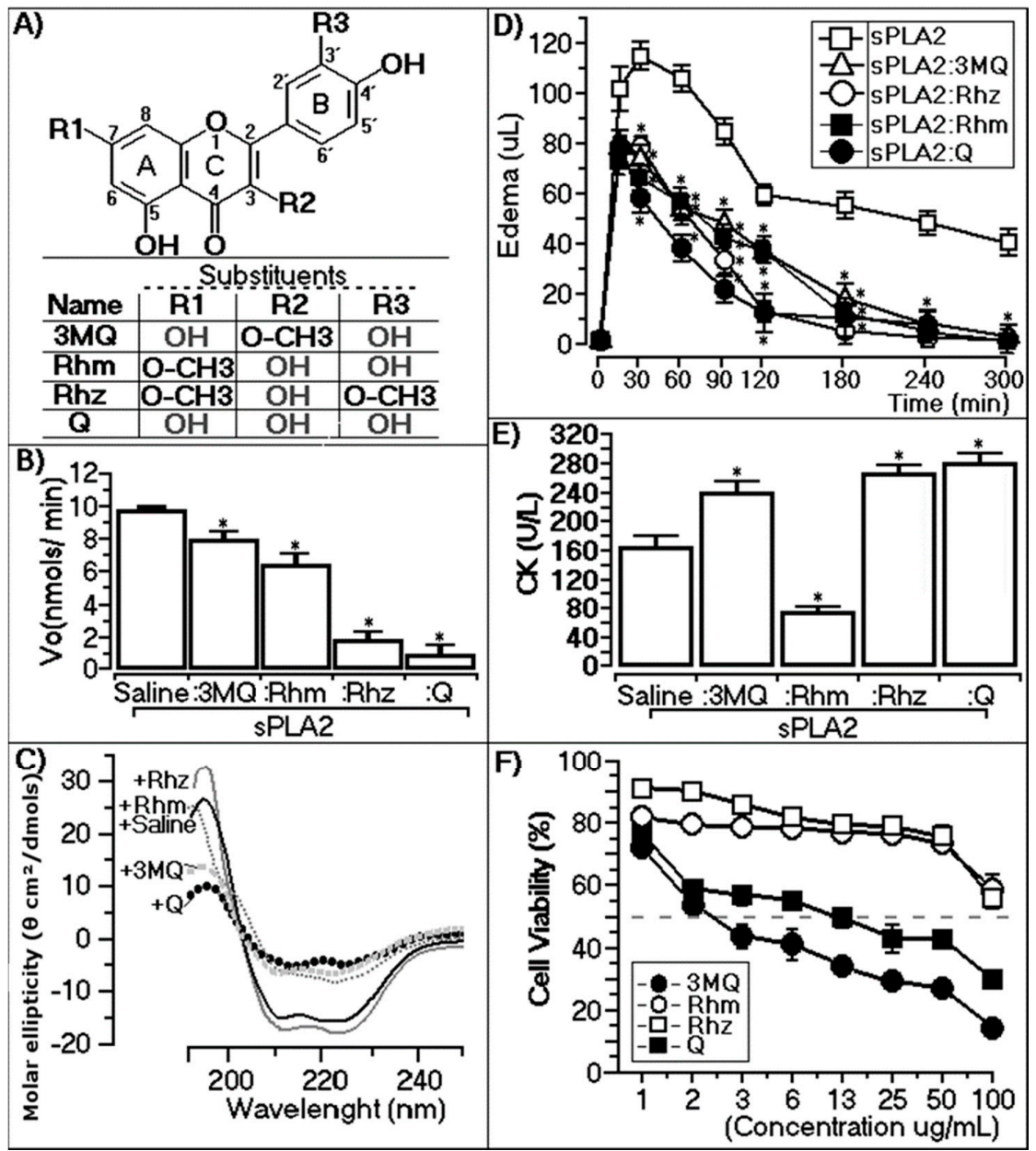

Figure 2. Structures of the quercetins assayed with the enzymatic, circular dichroism, edema, creatine kinase levels, and cytotoxic assays. (A) The structures of all flavonols assayed here and R1, R2, and R3 indicated the principal substituents found in all of the flavonols; (B) The effect of the previous treatment of the sPLA2 samples on the enzymatic activity after $30 \mathrm{~min}$ compared with native sPLA2. $3 \mathrm{MQ}, \mathrm{Rhm}, \mathrm{Rhz}$, and Q. Each column represents the mean and SD of six replicates $(n=6)$, and the asterisk $\left(^{*}\right)$ means $p<0.05$; (C) CD spectra of isolated sPLA2 (saline) and all quercetins incubated with the enzyme. Data over the range of 190-280 $\mathrm{nm}$ are shown and are expressed in theta machine units in molar ellipticity $\left(\theta \mathrm{cm}^{2} / \mathrm{dmols}\right)$, and each spectrum represents the analysis of three CD runs; (D) Graphic of the edema performed after $30 \mathrm{~min}$ of administration of the four quercetins evaluated (10 $\mu \mathrm{g}$ protein and $12.5 \mu \mathrm{g}$ compound). The results are expressed as the mean \pm standard deviation $(n=5)$, and the * means $p<0.05$. We used the ANOVA and Bonferroni a posteriori tests; (E) Myotoxic activity of native and pretreated SPLA2 via measurement of the creatine kinase assay. Each column is shown as the mean and SD of $n=5$ for each sample including saline, and ANOVA was used as the statistic assay with Dunnett as the a posteriori test. The ${ }^{*}$ shows groups with significant differences with sPLA2 $(p<0.05)$; (F) To evaluate the cytotoxic potential of all compounds, MTT (3-(4, 5-dimethylthiazolyl-2)-2,5-diphenyltetrazolium bromide) assay was performed with the J774 macrophages. Cells were incubated previously with each compound, and each point in the cell viability graph represents the mean and SD of 12 experiments.

\subsubsection{CK Levels of Chemically-Treated sPLA2}

Named bothropstoxin II (BthTX-II), the PLA2 from B. jararacussu induced a rapid increase in plasma creatine kinase levels [14]. Thus, if compounds inhibit this enzyme, lower CK levels were observed, indicating less muscle damage. In this way, the CK levels were quantified to compare 
the compounds' potential to decrease muscle injury. The results showed different activities for each compound. Q, 3MQ, and Rhz incubated with sPLA2 do not decrease the damage of this enzyme, and among these groups, CK levels were similar. By the other side, sPLA2 previously treated with Rhm potentially decreased CK release (Figure 2E). These data suggest that Rhm-treated sPLA2 neutralizes the muscle injury effect of native sPLA2 from Bothrops jararacussu. The structural analysis of all flavonols assayed here shows that the methylation in the A ring of Rhm is important for neutralization of the CK levels.

\subsubsection{Cytotoxic Assay of Methylated Quercetins}

To evaluate the cytotoxic potential of all compounds, MTT assay was performed with the J774 cell lineage. Figure $1 \mathrm{~F}$ shows the different cell responses of J774 cell lineage to quercetins. 3MQ and $Q$ revealed a higher toxicity with $C_{50}=3566$ and $10,371 \mu \mathrm{g}$, respectively. Otherwise, Rhm and Rhz showed no toxicity toward J774 cell lineage. The analyses of these results suggest that replacement of the 3-OH group with the $\mathrm{O}-\mathrm{CH} 3$ group in the $\mathrm{C}$ ring is involved with cytotoxic effects of $3 \mathrm{MQ}$ and $\mathrm{Q}$ (Figure 2D).

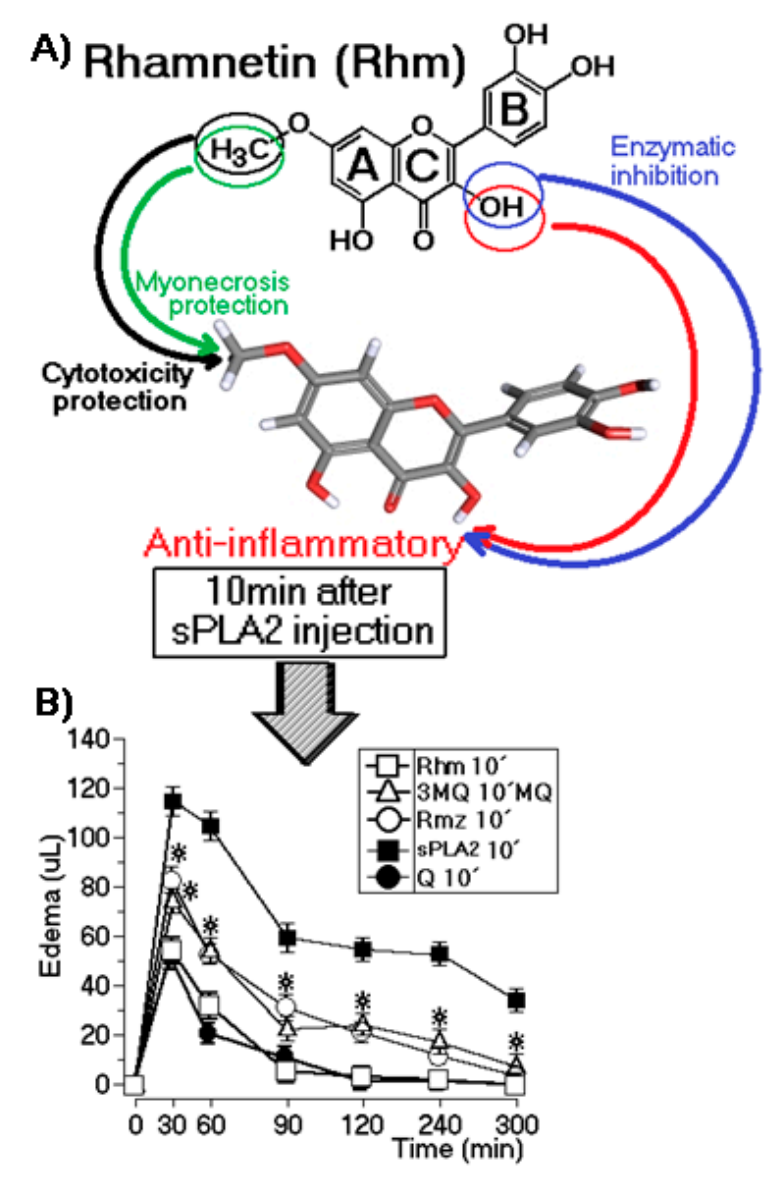

Figure 3. Structure-function relation between molecular regions of Rhm and its activities. (A) Molecular structure of $\mathrm{Rhm}$ in which the 3-OH in the $\mathrm{C}$ ring should lead to enzymatic and pharmacological inhibition and $\mathrm{OCH}_{3}$ in the A ring should lead to cytotoxic and myotoxic protection; (B) Flavonol injection after $10 \mathrm{~min}$ of sPLA2 application (10 $\mu \mathrm{g}$ protein and $12.5 \mu \mathrm{g}$ compound). The results are expressed as the mean \pm standard deviation $(n=5)$, and the * means $p<0.05$ using the ANOVA and Bonferroni a posteriori tests. 


\subsection{Edema Assay After Injection of sPLA2}

In Figure 1, we summarize the effects of the chemical treatment of sPLA2 with 3MQ, Rhm, Rhz, and $\mathrm{Q}$, and we concluded that Rhm has significant characteristics that include the presence of structural elements that specifically neutralize or strongly diminish the enzymatic activity of the pharmacological effects induced by sPLA2 from Bothrops jararacussu and do not induce significant cytotoxic activity. In the second edema assay, we injected each flavonol in the animals group $10 \mathrm{~min}$ after injection of sPLA2. Figure 3 shows that Rhm and Q essentially abolished edema induced by sPLA2, and both flavonols eliminated the edema 80 min after injection of sPLA2, whereas 3MQ and Rhz eliminated edema $4 \mathrm{~h}$ after injection of sPLA2.

\section{Discussion}

Plant extracts are characterized by the presence of active compounds and studies reveal the PLA2 inhibitory potential of extracts and isolated compounds. Crude aqueous extracts of Casearia sylvestris, Piper umbellatum, and Piper peltatum show this inhibitory activity [15-20]. Numerous studies have shown the anti-inflammatory and antioxidant activities of flavonoids and $Q$ is widely distributed in vegetables and fruits $[8,13]$. Its potential and distribution highlight the search for new molecules and the need to understand their structures and functions. The methylation of polyphenolic compounds seems to be the second most significant conjugation reaction from a nutritional and metabolic point of view [21].

There are studies that have evaluated the effect of flavonoids and glycosylated flavonoids on the course of the enzymatic and pharmacological activity of secretory phospholipases A2 [5,6]. Moreover, these studies deserve further efforts to elucidate the mechanism of action of these types of flavonoids on sPLA2, including studies of the conformational changes of flavonoids that modify their antioxidant properties to pro-oxidants, and these mechanisms should be better understood. The chemical structure of polyphenols gives them the ability to act as free radical scavengers. The type of compound and the degree of methylation influence this capacity, and the number of hydroxyl groups is another parameter that determines the antioxidant activity [22]. Thus, within molecular logic, and with substantial data showing the antioxidant effects of various flavonoids, it would be assumed that any protective or neutralizing effect of flavonoids on sPLA2 could be associated with the presence of different numbers of $\mathrm{OH}$ moieties in the $\mathrm{B}$ ring of the flavonols. These characteristics may contribute to flavonoid's antioxidant activity as well as its toxicity $[23,24]$. Despite the relevant role of sPLA2 in the course of the inflammatory process, there are not methylated flavonoid studies on the enzymatic and pharmacological activity of sPLA2.

Results presented herein about the treatment of sPLA2 samples in the presence of $Q$ and its derivatives clearly showed that it is not only the hydroxyls present in these flavonoids that are capable of neutralizing the pharmacological and enzymatic activities of sPLA2 from Bothrops jararacussu. The combination of methyl groups, the hydroxyl moiety present in the $C-3$ of the $C$ ring and $C-{ }^{\prime} 4$ of the B ring are shown to be essential to inhibit the enzymatic activity of sPLA2, as are the groups responsible for the neutralization of the edematogenic effects induced by this SPLA2 in this study. It can be accounted for because the $\mathrm{C}$ and $\mathrm{B}$ rings of some flavonoids may play a crucial role in the interaction of these compounds with the catalytic site of sPLA2 [5]; however, in the case of Rhm, the presence of the $\mathrm{OH}$ group in the $\mathrm{C}$ ring is crucial to decrease both the edematogenic and enzymatic activities of sPLA2. Besides that, the hydroxyl group present in the C-' 4 also shows an enzymatic inhibitory role. In addition, our results showed that the methyl group present in the A ring of Rhm can be responsible to the absence of cytotoxicity and inhibition of high CK levels induced by sPLA2 from B. jararacussu venom. Once macrophages are essential in the primary response in inflammation [25], $\mathrm{Rhm}$ is revealed to be a compound that inhibits inflammation without impairing the viability of the body's natural defence.

One important point is that the methylation of flavonoids may increase their hydrophobicity and, thus, increase the strength of the hydrophobic contacts between the protein and the flavonoid [26,27]. 
Studies with quercetrin reveal a high inhibition of sPLA2 from Crotalus durissus terrificus, possibly due the molecular interactions between the compound and the protein, as hydrogen bonding and hydrophobic interactions. The electrostatic interactions were observed between quercetrin and the amino acid residues Gly 30, Gly 32, His48, and Asp 49 and $\mathrm{Ca}^{2+}$ ion of sPLA2 leading to structural changes on the protein These interactions involves amino acids from de $\mathrm{Ca}^{2+}$-binding loop (e.g., Gly 30 ) and catalytic site (e.g., Asp 49 and His 48) [5]. Thus, besides the essential role of 3-OH to inhibit sPLA2, 4'-OH of Rhm can interact with Gly-30 of the protein leading to a higher decrease of its activity. These data suggest an essential role of hydroxyls on the interactions between the compound and sPLA2 and its following inhibition.

The circular dichroism clearly shows that, in the case of sPLA2, both methylations and the presence of hydroxyls can change the CD spectrum of sPLA2. Q strongly decreased sPLA2 $\alpha$-helix and shows the higher enzymatic inhibition. Despite Rhz exhibit also a potent inhibition of the enzyme, $\mathrm{CD}$ data revels that this compound do not leads strong modifications in sPLA2, conserving the structure. High structure modification is observed in $3 \mathrm{MQ}$, however, this change leads a decrease in the inhibition activity. Rhm interact with the enzyme besides exhibit an inhibitory potential. In this study, the presence of $\mathrm{OCH} 3$ on the catechol group increase sPLA2 inhibition, without strongly changing the enzyme structure. Despite the presence of $\mathrm{OCH} 3$ on the $\mathrm{B}$ ring, leading to a higher inhibition activity than $\mathrm{Rhm}$, this methylation leads to high toxicity and high $\mathrm{CK}$. Thus, 3-OH presence is also associated with sPLA2 inhibition, and methylation on the A ring brings no toxicity and lower CK. Higher interaction with sPLA2 of compounds with an absence of 3-OH was observed in 3MQ in this study and in quercetin [5]. These data are robust enough to show that methylation in the A ring is important to essentially abolish the cytotoxic and muscle damage effects via a free radical neutralizing-dependent pathway.

All flavonoids tested in this work are methylated derivatives of $Q$, which occurs naturally and is found in several species of phytochemical interest. In the case of $\mathrm{Rhm}$, there is considerable evidence showing that this particular flavonoid exerts its anti-inflammatory activity through two basic mechanisms: via envelope suppression of free radicals and by pro-inflammatory mediators [27]. These results show that the myonecrosis induced by several basic sPLA2s, such as sPLA2 from this work, would involve a strong increase in oxidative cellular stress, and the antioxidant capacity of Rhm would be very interesting for treatment of muscular degeneration induced by this protein. In vivo, all quercetins showed co-protection effects, revealing a decrease in paw edema at all times. The co-protection effect of $Q$ was elucidated in another study $[28,29]$, and its effect on chronic inflammation was higher than hesperidin (glycosylated and methylated quercetin). As it is known, there is a greater potential for aglycone flavonoids in terms of antioxidant activity in relation to the glycosylated forms $[28,29]$. This lowest potential is due to the hydroxyl substitution at the C-3 position in the $\mathrm{C}$ ring with a methylated or glycosylated group as a result of a decrease in $\mathrm{OH}$ and the changes in the molecular conformation of hydroxyl group. The flavonols with $\mathrm{OH}$ in the $\mathrm{C}-3$ position of the $\mathrm{C}$ ring are planar; thus, compounds are able to conjugate and relocate their electrons, as well as increase the radical phenoxyl stability of the flavonoid. Therefore, $3-\mathrm{OH}$ absence results in a twist on the $\mathrm{B}$ ring changing the antioxidant potential [24,28,29]. In this study, 3MQ reveals a loss of its sPLA2 inhibition activity; it also shows high cytotoxicity and CK. These data suggest the essential role of methylations in the A ring, the planar conformation's maintenance due to the presence of 3-OH and catechol group, besides the $\mathrm{OH}$ interactions between compound and protein to lead an inhibitory potential plus no toxicity against the immune system.

A decrease in paw edema was observed in Cassia sophera Linn, and this species has Rhm in its composition. In addition, Coriandrum sativum L. and Prusmus cerasus L. revealed the presence of Rhm, highlighting the potential of dietary species in phytochemical studies due to their benefits [11,12,30-34]. The suppression of the free radicals and pro-inflammatory mediators of Rhm would possibly inhibit of JNK and p38 MAPK activities by decreasing the COX2 pathway [11]. These pathways are important in the inflammation route, and our work shows that Rhm is beyond this activity; however, Rhm 
can both modulate and modify the action of sPLA2, thereby decreasing inflammation not only by maintaining inflammatory stimuli, but by also neutralizing enzymatic and pharmacological effects of sPLA2. In addition, in this work, Rhm and Q abolished the inflammatory effect induced by sPLA2 within $10 \mathrm{~min}$ after its injection-i.e., even after the onset of inflammatory process—Rhm and $Q$ were effective for edema neutralization (Figure 2). However, the cytotoxicity results showed that the best choice is Rhm, and the fact that this flavonoid has molecular regions involved in the inactivation of sPLA2 (Figure 2), reveals that this compound inhibits the action of sPLA2 by neutralizing the protein, itself, and protecting the cell from the effects of free radicals. Studies reveal a protection function of catechol moiety of $Q$, improving cellular uptake, metabolic stability, and lower toxicity of the methylation in Q. Additionally, structural modifications at the 5 or 7 position preserve most of the antioxidant capacity and this feature is observed in Rhm, once methylation occurs at C-7 [35].

Studies reveal that nonsteroidal anti-inflammatory drugs (NSAIDs) are the most commonly used drugs in inflammatory diseases. However, these drugs inhibit cyclooxygenase (COX) and COX-1 inhibition leads to gastrointestinal and renal side effects [36]. The enzymatic reaction involved in prostaglandin production by activation of COX is a two-step reaction: cyclooxygenase catalyses the formation of PG from arachidonic acid and a subsequent peroxidase reduces hydroperoxides (PGG2) and activates the cyclooxygenase and the peroxidase activity of COX can also generate reactive oxygen species. Thus, there is no total certainty of inhibiting COX-2 without inhibiting COX-1 and there is still a third group of COX (COX-3), which are inhibited by the same COX-1 inhibitory drugs [37]. It is also important to remember that all COX-2 drugs target the activity of converting arachidonic acid to prostaglandin, but forget that COX is comprised of bifunctional enzymes, where the reactions of bis oxygenase and peroxidase occur at distinct sites, which are structurally and functionally interconnected. NSAIDs bind specifically to the arachidonic acid binding site, but do not inhibit the peroxidase site that remains active, and COX-1 is found in most tissues and is related to the production of prostanoids involved in homeostasis processes in the body [38]. Thus, by looking at the entire spectrum of COX-2, COX-1, and COX-3, the search for an inhibitory drug with inflammatory activity as a function of the specific inhibition of sPLA2 is complex, since the inhibition is not complete and the production of prostanoids is physiological, and COX-1 can also be modulated.

In turn, in this study it is believed that the structure and molecular conformation of Rhm has anti-inflammatory activity and did not induce toxicity to cell lineages, nor to the experimental model; therefore, it can be considered a prototype anti-inflammatory drug.

\section{Materials and Methods}

\subsection{Flavonoids and Reagents}

To understand the effects of flavonoids on edema, muscle damage and the cytotoxic effects of $3 \mathrm{MQ}, \mathrm{Rhm}, \mathrm{Rhz}$, and $\mathrm{Q}$, each of these were obtained commercially from Sigma-Aldrich (St. Louis, MO, USA) All other chemicals, reagents, and kits were purchased from Sigma-Aldrich ${ }^{\circledR}$, Bio-Rad (Hercules, CA, USA), Cayman Chemical (Ann Arbor, MI, USA), and BIOMOL International (Farmingdale, NY, USA).

\subsection{Isolation, Enzymatic Kinetics, and Spectroscopic Evaluation of sPLA2}

\subsubsection{Purification of sPLA2 from Bothrops jararacussu}

The dried venom (35 mg) was dissolved in $0.05 \mathrm{M}$ of ammonium bicarbonate buffer (buffer A) followed by centrifugation $(4500 \times g$ for $3 \mathrm{~min})$. The supernatant was studied via an HPLC system Jasco system) coupled to the TSKgel SP-5PW $(7.5 \mathrm{~cm} \mathrm{ID} \times 7.5 \mathrm{~cm} \cdot \mathrm{L})$ Tosoh Bioscience column (Minato-Ku, Japan). sPLA2 was collected using a non-linear gradient with buffer B (ammonium bicarbonate $1.0 \mathrm{M}$ ) at a constant flow rate of $1.0 \mathrm{~mL} / \mathrm{min}$. The chromatography was monitored at $280 \mathrm{~nm}$, and the fraction obtained was lyophilized and stored at $-20^{\circ} \mathrm{C}$. Once the phospholipase A2 enzyme activity of the 
corresponding fraction was confirmed, the active sPLA2 underwent a new chromatographic step on a reverse phase HPLC using a C5 semi-analytical column. In this chromatographic step, fractionation of sPLA2 was performed using C5 reverse phase chromatography, and the chromatographic column was pre-equilibrated with buffer A $(0.1 \%$ TFA) for $30 \mathrm{~min}$ at a flow rate of $1 \mathrm{~mL} / \mathrm{min}$. Samples of sPLA2 ( $1 \mathrm{mg}$ ) were dissolved in $250 \mu \mathrm{L}$ of buffer A and separated using the chromatographic column. Elution of the sPLA2 was performed with a continuous linear gradient of buffer B $(66 \%$ Acetonitrile in $0.1 \%$ TFA), and the monitoring of the chromatographic profile was at $280 \mathrm{~nm}$.

\subsubsection{Enzymatic Characterization of sPLA2}

The inhibitory potential of the quercetins against sPLA2 were observed. The enzyme was dissolved in a $0.9 \% \mathrm{NaCl}$ saline solution at a final concentration of $1 \mathrm{mg} / \mathrm{mL}$. sPLA2 samples were incubated with the quercetins in microplates for $20 \mathrm{~min}$ at room temperature in the presence of a chromogenic substrate for phospholipase (NOBA). The substrate was solubilized in acetonitrile at $1 \mathrm{mg} / \mathrm{mL}$. To evaluate the inhibitory potential of the quercetins, sPLA2 was incubated with $0.25 \mathrm{mg} / \mathrm{mL}$ of the compounds for $30 \mathrm{~min}$. Both were added to $0.02 \mathrm{M}$ Tris- $\mathrm{HCl}$, $0.15 \mathrm{M} \mathrm{NaCl}$, and $1 \mathrm{mM} \mathrm{CaCl} 2$ ( $\mathrm{pH}$ 8) buffer for analysis via a SPECTRA MAX spectrophotometer (Molecular Devices, Sunnyvale, CA, USA) at a wavelength of $405 \mathrm{~nm}$. The measurements were performed throughout the incubation time $(90 \mathrm{~min})$ with five-minute intervals between readings. To calculate the percentage of inhibition, the rate of substrate consumption (slope of the line) was calculated using the formula

$$
\frac{\left(\text { Vo }_{P L A 2}-\text { Vo }_{\text {incubated }}\right)}{\text { Vo }}+100
$$

The data were expressed in percentage, and the error is in percentage points.

\subsubsection{Circular Dichroism (CD)}

J-815 CD Spectrometer (Jasco, São Paulo, Brazil) was used to evaluate the secondary structure of proteins (alpha helices, beta sheets, turns, and random secondary structures) in solution. It is characterized as a fast and economical method due to the small quantities of samples required. In this technique, polarized light is used in the distal ultraviolet (UV) range (from 180 to $260 \mathrm{~nm}$ ). This technique allows the evaluation of the structural integrity of proteins, conformational changes, and processes of denaturation (unfolding) and renaturation (folding), making it possible to estimate the composition of the elements in the secondary structure of this macromolecule. The circular dichroism analysis was performed with $0.1 \mathrm{mg} / \mathrm{mL}$ of sPLA2, and the compounds were incubated at the same concentration (1:1). The isolated compounds were also used to evaluate the possible interference in the tests. The analysis was performed to eight convolutions, and data were treated by Spectra Manager.

\subsection{Pharmacological Assay}

\subsubsection{Paw Edema Evaluation}

In vivo experimental models were performed to evaluate the inhibition of acute inflammation caused by purified sPLA 2 using randomly-chosen Swiss female mice $(\sim 25 \mathrm{~g}, n=5)$. In vivo experiments were performed only after in vitro investigation of the inhibition or interaction activities of the compounds with sPLA2. Mice were injected with $50 \mu \mathrm{L}(0.5 \mu \mathrm{g} / \mathrm{g}$ animal/12.5 $\mu \mathrm{g}$ per animal $)$ of the compounds via peritoneal injection. After $30 \mathrm{~min}$, via right posterior subplantar injection, $20 \mu \mathrm{L}(10 \mu \mathrm{g})$ of PLA2 solution $(n=5)$ was inoculated. A saline solution $(\mathrm{NaCl} 0.9 \%)$ was used for negative control. Six groups were made: (1) Saline; (2) sPLA2; (3) sPLA2:3MQ; (4) sPLA2:Rhm; (5) sPLA2:Rhz; and (6) sPLA2:Q. The volume of the paws was monitored using the LE7500 Digital Plethysmometer (Panlab, Harvard Apparatus, Cornellà, Spain) for $4 \mathrm{~h}$. After the tests, the mice were anaesthetized and sacrificed via cervical dislocation. In vivo experiments were performed 
according to the institutional rules and they were approved by the ethics committee from UNESP, number 008-CEUA.

\subsubsection{CK Level Measurement}

In total, $20 \mu \mathrm{L}(2.5 \mu \mathrm{g})$ of the compounds previously incubated for 30 min with sPLA2 $(n=5)$ were injected into the gastrocnemius muscle. After an average of $30 \mathrm{~min}$, the animals' blood was harvested from the tail in a heparinized tube, which was centrifuged and frozen for further analysis. Control groups $(n=5)$ were submitted to the same procedure as the treated animals but were inoculated with $20 \mu \mathrm{L}$ of $0.9 \% \mathrm{NaCl}, 20 \mu \mathrm{L}(2.5 \mu \mathrm{g})$ of the purified compounds or $20 \mu \mathrm{L}(10 \mu \mathrm{g})$ of isolated sPLA2. After the tests, the mice were sacrificed via cervical dislocation. Seric creatine kinase (CK) levels were determine the according to the manufacturer of the kit (Bioliquid, Pinhais, Brazil).

\subsection{Cytotoxic Effects}

To evaluate the cytotoxic effects of the quercetins, $2 \times 10^{5} \mathrm{~J} 774$ cells were cultured in R10 medium with $3 \mathrm{MQ}, \mathrm{Rhm}, \mathrm{Rhz}$, and Q (100.00 to $0.78 \mu \mathrm{g} / \mathrm{mL})$. As a negative control, macrophages were cultivated in the medium and in DMSO as the vehicle solution (never exceeding $1 \% v / v$ ). After $24 \mathrm{~h}$, the cell viability was analysed via the MTT method. This cell lineage was employed in the present work as a model for cytotoxicity, as previously studied [39,40]. From a biological point of view, this cell lineage can be used as a prediction of the action of studied molecules on the immune system. Cytotoxic concentrations 50\% (CC 50 ) was estimated using GraphPad Prism 5.0 software (La Jolla, CA, USA) for plotting and statistical analysis.

\subsection{Statistical Analyses}

Data are expressed as the means \pm standard deviations. The results were analyzed by analysis of variance (ANOVA) of one or two routes followed by the Dunett or Bonferroni a posteriori test. Values of $p<0.05$ were considered significant.

\section{Conclusions}

Flavonoid methylations may be extremely interesting for the generation of structural and functional variability. In the case of $\mathrm{Rhm}$, the methylation position on the $\mathrm{Q}$ skeleton gave rise to a compound that may be extremely valuable from a therapeutic point of view. This study shows that the methylation position changes the compound's function and, among the evaluated quercetins, $\mathrm{Rhm}$ is the best choice, exhibiting sPLA2 inhibitory activity, no cytotoxicity, and lower CK levels.

Acknowledgments: Thanks to UNESP, UNIFESP, and CNPq for providing some funds for maintenance of the staff involved in the project, and CNPq for financial support.

Author Contributions: M.H.T. and D.d.O.T. conceived and designed the experiments. M.N.B., H.H.G., C.F.B.R., and C.R.d.C.C. performed the experiments. L.F.D.P. and M.D.L. contributed to the cytotoxic assay. All authors contributed to the analysis. M.N.B. wrote the paper.

Conflicts of Interest: We wish to confirm that there are no known conflicts of interest associated with this publication and that there has been no significant financial support for this work that could have influenced its outcome.

\begin{tabular}{ll}
\multicolumn{2}{l}{ Abbreviations } \\
sPLA2 & Secretory phospholipase A2 \\
Q & Quercetin \\
3MQ & 3-O-Methylquercetin \\
Rhm & Rhamnetin \\
Rhz & Rhamnazin
\end{tabular}




\section{References}

1. Oliveira, S.C.B.; Fonseca, F.V.; Antunes, E.; Camargo, E.A.; Morganti, R.P.; Aparício, R.; Toyama, D.O.; Beriam, L.O.S.; Nunes, E.V.; Cavada, B.S.; et al. Modulation of the pharmacological effects of enzymatically-active PLA2 by BTL-2, an isolectin isolated from the Bryothamnion triquetrum red alga. BMC Biochem. 2008, 9. [CrossRef] [PubMed]

2. Cotrim, C.A.; de Oliveira, S.C.B.; Diz Filho, E.B.S.; Fonseca, V.F.; Baldissera, L., Jr.; Antunes, E.; Ximenes, R.M.; Moteiro, H.S.A.; Rabello, M.M.; Hernandes, M.Z.; et al. Quercetin as an inhibitor of snake venom secretory phospholipase A2. Chem. Biol. Interact. 2011, 189, 9-16. [CrossRef] [PubMed]

3. Nevalainen, T.J.; Haapamaki, M.M.; Gronroos, J.M. Roles of secretory phospholipases A2 in inflammatory diseases and trauma. BBA Mol. Cell Biol. Lipids 2000, 1488, 83-90. [CrossRef]

4. Ximenes, R.M.; Rabello, M.M.; Araújo, R.M.; Silveira, E.R.; Fagundes, F.H.R.; Diz-Filho, E.B.S.; Buzzo, S.C.; Soares, V.C.G.; de O. Toyama, D.; Gaeta, H.H.; et al. Inhibition of neurotoxic secretory phospholipases A2 enzymatic, edematogenic, and myotoxic activities by harpalycin 2, an isoflavone isolated from Harpalyce brasiliana benth. Evid. Based Complement. Alternat. Med. 2012, 2012, 1-9. [CrossRef] [PubMed]

5. Toyama, D.O.; Gaeta, H.H.; de Pinho, M.V.; Ferreira, M.J.; Romoff, P.; Matioli, F.F.; Magro, A.J.; Fontes, M.R.; Toyama, M.H. An evaluation of 3-rhamnosylquercetin, a glycosylated form of quercetin, against the myotoxic and edematogenic effects of sPLA 2 from Crotalus durissus terrificus. Biomed. Res. Int. 2014, 2014, 1-11.

6. Toyama, D.O.; Ferreira, M.J.; Romoff, P.; Fávero, O.A.; Gaeta, H.H.; Toyama, M.H. Effect of chlorogenic acid (5-Caffeoylquinic Acid) isolated from Baccharis oxyodonta on the structure and pharmacological activities of secretory phospholipase A2 from Crotalus durissus terrificus. Biomed. Res. Int. 2014, 2014, 1-10.

7. Behling, E.B.; Sendão, M.C.; Francescato, H.D.C.; Antunes, L.M.G.; Bianchi, M.L.P. Flavonoid quercetin: General aspects and biologicals actions. Alim. Nutr. 2004, 15, 285-292.

8. $\quad$ Egert, S.; Wolffram, S.; Bosy-Westphal, A.; Boesch-Saadatmandi, C.; Wagner, A.E.; Frank, J.; Rimbach, G.; Mueller, M.J. Daily Quercetin Supplementation dose-dependently increases plasma quercetin concentrations in healthy humans. J. Nutr. 2008, 138, 1615-1621. [PubMed]

9. Morikawa, K.; Nonak, M.; Narahara, M.; Torii, I.; Kawaguchi, K.; Yoshikawa, T.; Kumazawa, Y.; Morikawa, S. Inhibitory effect of quercetin on carrageenan-induced inflammation in rats. Life Sci. J. 2003, 74, 709-721. [CrossRef]

10. Souza, K.C.B.; Schapoval, E.E.S.; Bassani, V.L. LC determination of flavonoids: Separation of quercetin, luteolin and 3-O-methylquercetin in Achyrocline satureioides preparations. J. Pharm. Biomed. Anal. 2002, 28, 771-777. [CrossRef]

11. Jnawali, H.N.; Lee, E.; Jeong, K.W.; Shin, A.; Heo, Y.S.; Kim, Y. Anti-inflammatory activity of rhamnetin and a model of its binding to c-jun NH2-terminal kinase 1 and p38 MAPK. J. Nat. Prod. 2014, 77, 258-263. [CrossRef] [PubMed]

12. Wagner, H.; Ertan, M.; Seligmann, O. Rhamnazin-und Rhamnetin-3-O-Trioside aus Rhamnus petiolaris. Phytochemistry 1973, 13, 857-860. [CrossRef]

13. Kuhnle, G.; Spencer, J.P.; Schroete, H.; Shenoy, B.; Debnam, E.S.; Srai, S.K.; Rice-Evans, C.; Hahn, U. Epicatechin and catechin are Omethylated and glucuronidated in the small intestine. Biochem. Biophys. Res. Commun. 2000, 277, 507-512. [CrossRef] [PubMed]

14. Gutiérrez, J.M.; Núñez, J.; Cintra, A.C.O.; Homsi-Brandeburgo, M.I.; Giglio, J.R. Skeletal muscle degeneration and regeneration after injection of bothropstoxin-II, a phospholipase A2 isolated from the venom of the snake Bothrops jararacussu. Exp. Mol. Pathol. 1991, 55, 217-229. [CrossRef]

15. Borges, M.H.; Soares, A.M.; Rodrigues, V.M.; Andrião-Escarso, S.H.; Diniz, H.; Hamaguchi, A.; Quintero, A.; Lizano, S.; Gutiérrez, J.M.; Giglio, J.R.; Homsi-Brandeburgo, M.I. Effects of aqueous extract of Casearia sylvestris (Flacourtiaceae) on actions of snake and bee venoms and on activity of phospholipases A2. Comp. Biochem. Physiol. B Biochem. Mol. Biol. 2000, 127, 21-30. [CrossRef]

16. Núñes, V.; Castro, V.; Murillo, R.; Ponce-Soto, L.A.; Merfort, I.; Lomonte, B. Nhibitory effects of Piper umbellatum and Piper peltatum extracts towards myotoxic phospholipases A2 from Bothrops snake venoms: Isolation of 4-nerolidylcatechol as active principle. Phytochemistry 2005, 66, 1017-1025.

17. Vishnawath, B.S.; Fawzy, A.A.; Franson, R.C. Edema-inducing activity of phospholipase A2 purified from human synovial fluid and inhibition by aristolochic acid. Inflammation 1988, 12, 549-561. [CrossRef] 
18. Vishnawath, B.S.; Gowda, V.T. Interaction of aristolochic acid with Vipera russelli phospholipase A2: Its effect on enzymatic and pathologic activities. Toxicon 1987, 25, 927-937. [CrossRef]

19. Vishnawath, B.S.; Kini, R.M.; Gowda, T.V. Characterization of three edema-inducing phospholipase A2 enzymes from Habu (Trimesurus flavoviridis) venom and their interaction with the alkaloid aristolochic acid. Toxicon 1987, 25, 501-515. [CrossRef]

20. Vishnawath, B.S.; Rao, A.G.A.; Gowda, T.V. Interaction of phospholipase A2 from Vipera russeli venom with aristolochic acid: A circular dichroism study. Toxicon 1987, 25, 939-946. [CrossRef]

21. Caoab, G.; Sofic, E.; Prior, R.L. Antioxidant and prooxidant behavior of flavonoids: Structure-activity relationships. Free Radic. Biol. Med. 1997, 22, 749-760.

22. Rahal, A.; Kumar, A.; Singh, V.; Yadav, B.; Tiwari, R.; Chakraborty, S.; Dhama, K. Oxidative stress, prooxidants, and antioxidants: The interplay. Biomed. Res. Int. 2014, 2014, 1-19. [CrossRef] [PubMed]

23. Kim, J.D.; Liu, L.; Guo, W.; Meydani, M. Chemical structure of flavonols in relation to modulation of angiogenesis and immune-endothelial cell adhesion. J. Nutr. Biochem. 2006, 17, 165-176. [CrossRef] [PubMed]

24. Moalin, M.; Strijdonck, G.P.; Beckers, M.; Hagemen, G.; Borm, P.; Bast, A.; Haenen, G.R. A planar conformation and the hydroxyl groups in the $\mathrm{B}$ and $\mathrm{C}$ rings play a pivotal role in the antioxidant capacity of quercetin and quercetin derivatives. Molecules 2011, 16, 9636-9650. [CrossRef] [PubMed]

25. Meng, L.X. Adipocytes, Macrophages and Inflammation. Ph.D. Thesis, University of Sydney, Sydney, Australia, 2014.

26. Camargo, E.A.; Santana, D.G.; Silva, C.I.; Teixeira, S.A.; Toyama, M.H.; Cotrim, C.; Landucci, E.C.; Antunes, E.; Muscara, M.N.; Costa, S.K. Inhibition of inducible nitric oxide synthase-derived nitric oxide as a therapeutical target for acute pancreatitis induced by secretory phospholipase A2. Eur. J. Pain. 2014, 18, 691-700. [CrossRef] [PubMed]

27. Oteiza, P.I.; Erlejman, A.G.; Verstraeten, S.V.; Keen, C.L.; Fraga, C.G. Flavonoid-membrane interactions: A protective role of flavonoids at the membrane surface? J. Immunol. Res. 2005, 12, 19-25. [CrossRef]

28. Zhang, W.; Li, B.; Guo, Y.; Bai, Y.; Wang, T.; Fu, K.; Sun, G. Rhamnetin attenuates cognitive deficit and inhibits hippocampal inflammatory response and oxidative stress in rats with traumatic brain injury. Cent. Eur. J. Immunol. 2015, 40, 35-41. [CrossRef] [PubMed]

29. Guardia, T.; Rotelli, A.E.; Juarez, A.O.; Pelzer, L.E. Anti-inflammatory properties of plant flavonoids. Effects of rutin, quercetin and hesperidin on adjuvant arthritis in rat. II Farmaco 2001, 56, 683-687. [CrossRef]

30. Soobrattee, M.A.; Neergheen, V.S.; Ramma-Luximon, A.; Aruoma, O.I. Phenolics as potential antioxidant therapeutic agents: Mechanism and actions. Mutat. Res. Fund. Mol. Mech. Mut. 2005, 579, 200-213. [CrossRef] [PubMed]

31. Jiang, J.S.; Shih, C.M.; Wang, S.H.; Chen, T.T.; Lin, C.N.; Ko, W.C. Mechanisms of suppression of nitric oxide production by 3-O-methylquercetin in RAW 264.7 cells. J. Ethnopharmacol. 2006, 103, 281-287. [CrossRef] [PubMed]

32. Mondal, A.; Rajalingam, D.; Maity, T.K. Anti-inflammatory effect of O-methylated flavonol 2-(3,4-dihydroxy-phenyl)-3,5-dihydroxy-7-methoxy-chromen-4-one obtained from Cassia sophera Linn in rats. J. Ethnopharmacol. 2013, 147, 525-529. [CrossRef] [PubMed]

33. Ozipek, M.; Çalis, I.; Ertant, M.; Ruedi, P. Rhamnetin 3-p-coumaroylrhamninoside from Rhamnus petiolaris. Phytochemistry 1994, 37, 249-253. [CrossRef]

34. Wei, B.L.; Lu, C.M.; Tsao, L.T.; Wang, J.P.; Lin, C.N. In vitro anti-inflammatory effects of quercetin 3-O-methyl ether and other constituents from Rhamnus species. Planta Med. 2001, 67, 745-747. [CrossRef] [PubMed]

35. Moalin, M. Quercetin and its Methylated Metabolites: The Chemical Basis of Activity. Ph.D. Thesis, Maastricht University, Maastricht, Netherlands, 2014.

36. Bacchi, S.; Palumbo, P.; Sponta, A.; Coppolino, M.F. Clinical pharmacology of non-steroidal anti-inflammatory drugs: A review. Antiinflamm. Antiallergy Agents Med. Chem. 2012, 11, 52-64. [CrossRef] [PubMed]

37. Schwab, J.M.; Schluesener, H.J.; Meyermann, R.; Serhan, C.N. COX-3 the enzyme and the concept: Steps towards highly specialized pathways and precision therapeutics? Prostaglandins Leukot. Essent. Fat. Acids 2003, 69, 339-343. [CrossRef] 
38. Font-Nieves, M.; Sans-Fons, M.G.; Gorina, R.; Bonfill-Teixidor, E.; Salas-Pérdomo, A.; Márquez-Kisinousky, L.; Santalucia, T.; Planas, A.M. Induction of COX-2 Enzyme and Down-regulation of COX-1 Expression by Lipopolysaccharide (LPS) Control Prostaglandin E2 Production in Astrocytes. J. Biol. Chem. 2012, 287, 6454-6468. [CrossRef] [PubMed]

39. Nattras, C.; Horwell, C.J.; Damby, D.E.; Brown, D.; Stone, V. The effect of aluminium and sodium impurities on the in vitro toxicity and pro-inflammatory potential of cristobalite. Environ. Res. 2017, 159, 164-175.

40. Leslie, L.J.; Vasanthi, B.P.; Jackson, P.; Mabiala, M.M.J.A.; Pallet, R.; Stillman, C.J.P.; Marshall, L.J. A comparative study of electronic cigarette vapor extracts on airway-related cell lines in vitro. Inhal. Toxicol. 2017, 29, 126-136. [CrossRef] [PubMed]

Sample Availability: Samples of the compounds sPLA2, 3MQ, Rhz, Rhm and Q are available from the authors.

(C) 2017 by the authors. Licensee MDPI, Basel, Switzerland. This article is an open access article distributed under the terms and conditions of the Creative Commons Attribution (CC BY) license (http:/ / creativecommons.org/licenses/by/4.0/). 